\title{
AFINAL DE CONTAS, POR QUE O BULLYING DEVE SER PROBLEMATIZADO DENTRO DAS ESCOLAS?
}

Marcos Vinicius Francisco

Programa de Pós-Graduação em Educação da Faculdade de Ciências e Tecnologia - UNESP. Email:

marcoseduca01@yahoo.com.br

\section{RESUMO}

A presente pesquisa é fruto da dissertação de mestrado pelo programa de Pós Graduação em Educação da FCT/UNESP. A partir do aporte teórico da Teoria Histórico-Cultural, têm-se como objetivos apresentar a percepção de estudantes do Ensino Fundamental sobre situações nas quais eles tiveram que se colocar no lugar das vítimas do bullying escolar; bem como enfocar o papel da educação escolar na problematização de tal manifestação de violência. Os resultados apontam que vários estudantes expressam as marcas da não tolerância ou ausência de respeito aos que são tidos como "diferentes". Essa ausência de empatia, apenas reforça as diferenças que assolam o atual modo de viver. Problematizar tais diferenças e contradições é papel, também, da educação escolar, que meio do conhecimento científico pode conscientizar as pessoas que o bullying escolar é um produto histórico-cultural construído a partir das relações sociais presentes no sistema capitalista.

Palavras-Chave: Bullying escolar; Estudantes; Violência; Histórico-cultural; Capitalismo.

\section{INTRODUÇÃO}

Um dos espaços mais propícios para se problematizar o tema violência, bem como proporcionar elementos e espaços para uma intervenção articulada ao contexto mais amplo da sociedade, são as escolas. Elas deveriam priorizar a importância de se repensar a dimensão humana nas relações sociais. Todavia, essa dimensão aparece relegada, isto é, quando evidenciada, os aspectos de competitividade, seletividade e instrumentalização são vistos como prioridades.

De acordo com Abramovay (2003a), por meio de suas investigações fica evidente a ambiguidade da escola e de sua função, no que concerne às representações dos estudantes. Para alguns ela é vista como um lugar para a aprendizagem, o que poderia facilitar uma inserção no mercado de trabalho e na sociedade. Por outro lado, muitos a consideram como um local de exclusão social, onde são reproduzidas e reforçadas situações de violência e discriminação.

Dentre as diversas formas de violência podem ocorrer no ambiente escolar, focar-se-á no bullying escolar nessa investigação. Nesse sentido, será adotada a conceituação apresentada por Francisco e Libório (2011) que amparados no referencial da Teoria Histórico-Cultural vão defender a influência dos aspectos histórico-culturais na produção das manifestações de violência e, por 
conseguinte, que evidencie o bullying como uma manifestação eminentemente humana e socialmente construída.

Destarte, Francisco e Libório (2011) apontam que:

Um aspecto que nos parece importante e necessário e que vem sendo negligenciado em diversos estudos seria compreender o assunto para além de determinismos biológicos, os quais justificam a condição de sujeitos predispostos às ocorrências do bullying. Dessa forma, poderíamos contribuir para a superação de uma compreensão individualizante desse fenômeno social, como se somente o agressor e a vítima fossem responsáveis pela sua ocorrência, sem considerar a força dos valores e crenças culturais, que inspiram práticas pouco empáticas e solidárias entre os sujeitos de nossa sociedade de forma mais ampla (FRANCISCO \& LIBÓRIO, 2011, p. 65).

Sustenta-se tal pressuposto a partir de autores como Vigotski $(1995,2001)$ e Leontiev (1978) que apontam a necessidade de se estudar a natureza social do ser humano; bem como pelo entendimento de que não são os aspectos individuais que promovem as variações entre os sujeitos, mas o engajamento e contato com as atividades produzidas dentro da cultura humana, que são socialmente estruturadas e desigualmente oportunizadas aos sujeitos.

Posto isso, as escolas se tornam ambientes importantíssimos na superação dos preconceitos instalados, ou na desconstrução de valores que aparentemente ganham uma conotação homogênea perante a sociedade. Assim, os professores passam a ser vistos como os mediadores desse processo de conhecimento, em contato com o contexto local no qual estão inseridos em que sua prática ganha destaque.

Nessa perspectiva a educação passa a ser olhada de outra forma: as crianças, adolescentes e demais pessoas que estão em seu interior são percebidas como sujeitos que estão num processo dinâmico de interação sócio-cultural. Diante disso, ao surgirem os conflitos entre escolares, não devemos transferir a culpa para determinadas atitudes a certos sujeitos que são excluídos por seus pares, mas sim perceber as influências contextuais que favorecem formas de violência, e porque não dizer, de reprodução de injustiças sociais vividas pelos sujeitos nos contextos sociais mais amplos.

Diante dos elementos aqui apresentados, e assentados no referencial da Teoria HistóricoCultural, a presente pesquisa tem como objetivo apresentar a percepção de estudantes do Ensino Fundamental sobre situações nas quais eles têm que se colocam no lugar das vítimas do bullying escolar, bem como enfocar o papel da educação escolar na problematização do bullying. 


\section{METODOLOGIA}

A presente pesquisa visou problematizar o bullying escolar, a partir do enfoque da Teoria Histórico-Cultural, baseada no Materialismo Histórico Dialético.

Ressalta-se a importância de se ter um método coerente e que dê conta de auxiliar efetivamente nos desdobramentos de uma pesquisa. As pesquisas embasadas na Teoria HistóricoCultural primam pela busca dos aspectos qualitativos dos processos que estuda, o quantitativo é apenas um momento no processo da pesquisa, necessário à organização dos dados de um experimento, por exemplo.

Vigotski $(1995,2001)$ fazia questão de salientar que utilizar-se do materialismo histórico dialético para analisar os fenômenos psicológicos não significa apenas citar trechos de Marx e Engels, como nas famosas "colchas de retalhos" presentes em obras da psicologia ocidental burguesa. Havia a necessidade de se criar uma Psicologia Geral, na qual o método proposto por Marx servisse de base para se pensar nos elementos que constituem a realidade objetiva e são incorporados a subjetividade humana em suas diferentes manifestações.

Partindo dessas premissas, adotou-se uma perspectiva teórica que vise problematizar as situações de bullying, para além de análises simplificadas em causas e efeitos para os envolvidos, como se os mesmos não fizessem parte de um todo social mais amplo. Acredita-se que há influências diretas relacionadas aos processos históricos, econômicos, políticos e culturais.

O estudo foi desenvolvido com adolescentes dos 9o anos do Ensino Fundamental em duas escolas da Rede Estadual de Ensino de Presidente Prudente-SP. Vale apontar, que a pesquisa foi aprovada pelo Comitê de Ética em Pesquisa da FCT/UNESP.

O instrumento de pesquisa utilizado foi o questionário SCAN-BULLYING elaborado pelas autoras portuguesas Almeida e Caurcel (2005) e versa sobre o entendimento que os alunos têm sobre o bullying escolar.

Assim, na escola A, a turma selecionada era composta por 36 alunos, sendo que desses 17 foram os que trouxeram os TCLE e participaram da pesquisa. Com relação à escola $B$, havia na turma selecionada 34 alunos, sendo que desses 20 mostraram-se favoráveis a participação no estudo. Assim, a amostra total constituiu-se de 37 sujeitos de ambas as escolas, a aplicação durou aproximadamente duas horas.

Os dados coletados no questionário foram tabulados a partir do software SPSS versão 12.0 e analisados em consonância com o referencial epistemológico destacado anteriormente. Nesse 
trabalho o foco das análises serão as questões que remetem a se colocar no lugar das vítimas, bem como reagiriam diante de situações idênticas as sofridas pelas vítimas do bullying escolar.

\section{RESULTADOS}

Quando perguntado aos alunos, se fossem a vítima da prancha, como se sentiriam, (Tabela 01) verifica-se que "nunca se sentiriam" invejosos $89,20 \%$, culpados $78,40 \%$ e orgulhosos $70,30 \%$. Entretanto, na escala "sempre se sentiriam": 51,40\% tristes, 45,90\% indiferentes ao ocorrido e $43,20 \%$ sozinhos e magoados.

Tabela 01. Opinião dos participantes sobre como se sentiriam caso fossem as vítimas

\begin{tabular}{|c|c|c|c|c|c|c|c|c|c|c|c|c|c|c|}
\hline \multirow{2}{*}{$\begin{array}{c}\text { Se você fosse a } \\
\text { vítima, como } \\
\text { se sentiria }\end{array}$} & \multicolumn{2}{|c|}{ Nunca } & \multicolumn{2}{|c|}{$\begin{array}{l}\text { Poucas } \\
\text { Vezes }\end{array}$} & \multicolumn{2}{|c|}{$\begin{array}{c}\text { Algumas } \\
\text { vezes }\end{array}$} & \multicolumn{2}{|c|}{$\begin{array}{l}\text { Muitas } \\
\text { vezes }\end{array}$} & \multicolumn{2}{|c|}{ Sempre } & \multicolumn{2}{|c|}{ Missing } & \multicolumn{2}{|c|}{ Total } \\
\hline & $F$ & $\%$ & $f$ & $\%$ & $f$ & $\%$ & $f$ & $\%$ & $f$ & $\%$ & $f$ & $\%$ & $f$ & $\%$ \\
\hline Culpado & 29 & 8,40 & & 3,10 & & 2,70 & 3 & 8,10 & 1 & 2,70 & 0 & 0,00 & 37 & \\
\hline So: & 5 & 0 & 7 & 3,90 & & 10 & 6 & 6,20 & 16 & & 0 & & 37 & \\
\hline Triste & 3 & 0 & & 10 & & 13,50 & 6 &, 20 & 19 & 10 & & 0 & 37 & 00 \\
\hline & 9 & 24,30 & 4 & 80 & 2 & 40 & 5 & 50 & 17 & 5,90 & 0 & 0 & 37 & ת \\
\hline Magoado & 2 & & $\varepsilon$ & 60 & & 0,80 & 7 & 90 & 16 & & 0 & 0 & 37 &, \\
\hline & 3 & & 8 & 60 & 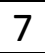 & 18,90 & 8 & 60 & 11 & & 0 & & 37 & \\
\hline & - & & 7 & 18,90 & & 10,80 & 3 & & 13 & & & 40 & 37 &, 00 \\
\hline Orgull & 26 & 70,30 & 4 & 10,80 & & 2,70 & 1 & 2,70 & 3 & 10 & 2 & 40 & 37 & 100,00 \\
\hline & 14 & 37,80 & 5 & 13,50 & 2 & 5,40 & 5 & 13,50 & 10 & 27,00 & 1 & 2,70 & 37 &, 00 \\
\hline & 5 & 13,50 & 5 & 13,50 & 1 & 10,80 & 8 & 21,60 & 14 & 37,80 & 1 & 2,70 & 37 & 100,00 \\
\hline Invejoso & 33 & 89,20 & 1 & 2,70 & 1 & 2,70 & 0 & 0,00 & 2 & 5,40 & 0 & 0,00 & 37 & 100,00 \\
\hline Outras & 0 & 0,00 & 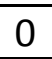 & 0,00 & 0 & 0,00 & 0 & 0,00 & 2 & 5,40 & 0 & 0,00 & 37 & 100,00 \\
\hline
\end{tabular}

Fonte: Pesquisa de Campo, 2009.

Com relação a esse aspecto fica evidente o como as situações de bullying podem desestabilizar os indivíduos. Outro problema refere-se ao fato de que tais situações, muitas vezes são tidas como naturais pelos adultos e professores, como parte do processo de amadurecimento dos jovens (FRANCISCO \& LIBÓRIO, 2009; MUNARIN, 2007), podendo trazer consequências muito drásticas às vítimas, no que se refere ao sentimento de pertencimento, bem como na sua autoestima e até mesmo na banalização das situações de violência.

Entretanto, é interessante destacar os alunos que mencionaram que se sentiriam indiferentes, caso fossem as vítimas. Deste modo, percebe-se a imposição de certas formas pelas quais o psiquismo vai sendo internalizado nos indivíduos, o que por vez ocasiona diferentes 
percepções diante da maneira que os indivíduos estão inseridos na sua cultura e percebem e interpretam a situação ao seu redor (MUNARIN, 2007). Nesse sentido, por mais que alguns alunos tenham êxito diante das provocações e perseguições, não podemos desconsiderar aqueles que precisam de ajuda.

Leontiev (1978, p.262) esclarece que a dimensão humana presente no homem advém de sua inserção social, a partir do contato com as produções e significações de uma dada cultura, criadas pela humanidade. Nesse sentido, não se pode perder de vista que o processo de hominização conduziu à vida a um modelo de organização social que tem como base o trabalho, bem como "que esta passagem modificou sua natureza e marcou o início de um desenvolvimento que, diferentemente do desenvolvimento dos animais, estava e está submetido não as leis biológicas, mas as leis sócio-históricas".

Diante da seguinte pergunta: “Em situações parecidas a esta (prancha), o que você faria?" (Tabela 02), obtiveram-se os seguintes resultados: do total de pesquisados, $81,10 \%$ escolheram a opção que "nunca" se colocariam ao lado do grupo de agressores, 51,40\% escolheram a mesma opção para não faço nada. Um ponto a ilustrar foram aqueles que disseram que "sempre" contariam a um professor $59,50 \%$. Com relação à resposta afasto-me dali, $37,80 \%$ disseram "sempre" fazer isso. E, no que tange à resposta, "ajudo o rapaz ou a menina", 35,10\% apontaram "sempre" ajudar as vítimas.

Almeida (2008) justifica que os papéis sociais que os alunos têm perante o grupo é que permitem estabelecer suas inter-relações. Assim, haverá aqueles que vão ajudar os agressores e contribuirão para proliferação dos maus tratos; aqueles que ao verem, mesmo que não intervenham diretamente, com sua presença podem intimidar ou não as agressões. $E$, ainda há aqueles que tomam partido e defendem o colega vitimizado. Em seus estudos, Pereira (2002) apontou que $20,80 \%$ e $9,10 \%$, respectivamente dos meninos e meninas não tiveram nenhum apoio de seus pares, no que tange aos maus tratos a que foram submetidos no ambiente escolar. 
Tabela 02. Opinião dos participantes sobre o que fariam em situações como a da prancha.

\begin{tabular}{l|c|c|c|c|c|c|c|c|c|c|c|c|c|c}
\hline \hline $\begin{array}{c}\text { Em situações } \\
\text { parecidas } \\
\text { (prancha), o } \\
\text { que você faria }\end{array}$ & \multicolumn{2}{|c|}{ Nunca } & \multicolumn{2}{c|}{$\begin{array}{c}\text { Poucas } \\
\text { Vezes }\end{array}$} & \multicolumn{2}{|c|}{$\begin{array}{c}\text { Algumas } \\
\text { vezes }\end{array}$} & \multicolumn{2}{c|}{$\begin{array}{c}\text { Muitas } \\
\text { vezes }\end{array}$} & \multicolumn{2}{|c|}{ Sempre } & \multicolumn{2}{|c|}{ Missing } & \multicolumn{3}{|c}{ Total } \\
\hline Não faço nada & 19 & 51,40 & 8 & 21,60 & 4 & 10,80 & 3 & 8,10 & 3 & 8,10 & 0 & 0,00 & 37 & 100,00 \\
\hline Afasto-me dali & 8 & 21,60 & 2 & 5,40 & 8 & 21,60 & 5 & 13,50 & 14 & 37,80 & 0 & 0,00 & 37 & 100,00 \\
\hline $\begin{array}{l}\text { Ajudo o } \\
\text { menino }\end{array}$ & 7 & 18,90 & 3 & 8,10 & 5 & 13,50 & 7 & 18,90 & 13 & 35,10 & 2 & 5,40 & 37 & 100,00 \\
\hline $\begin{array}{l}\text { Ponho-me do } \\
\text { lado do grupo }\end{array}$ & 30 & 81,10 & 0 & 0,00 & 2 & 5,40 & 1 & 2,70 & 3 & 8,10 & 1 & 2,70 & 37 & 100,00 \\
\hline $\begin{array}{l}\text { Conto a um } \\
\text { professor }\end{array}$ & 5 & 13,50 & 4 & 10,80 & 1 & 2,70 & 5 & 13,50 & 22 & 59,50 & 0 & 0,00 & 37 & 100,00 \\
\hline \hline
\end{tabular}

Fonte: Pesquisa de Campo, 2009.

Entender o porquê que alguns alunos não ajudam seus companheiros é algo que deveria ser mais estudado em pesquisas futuras. Essa falta de sensibilização deixa suas marcas na não tolerância ou ausência de respeito aos que são tidos como "diferentes". Assim, essa ausência de empatia, apenas reforça as diferenças que assolam o nosso modo de viver numa sociedade repleta de interesses e contradições. Problematizar tais diferenças, talvez, seja uma das formas de não ficarmos quietos a todas as impunidades que acontecem ao nosso redor, e pelas quais muitas vezes não fazemos nada, num processo pelo qual "fingimos" não ver ou sentir.

Outro ponto que merece nossa atenção são os alunos que gostariam de ajudar as vítimas, mas que por receio de sofrerem as mesmas consequências adotam certa distância ou não posicionamento diante dos casos de vitimização entre pares (MUNARIN, 2007). Portanto, muitas vezes somos levados a agir em função das expectativas de outras pessoas, especialmente do grupo ao nosso redor, o que reforça atitudes estereotipadas e que permeiam o imaginário social como as aceitas perante os outros.

\section{DISCUSSÃO}

Os temas relacionados à violência, respeito às diversidades culturais e sociais, bem como o preconceito nas suas diferentes faces deveriam ganhar relevância nos currículos da Educação Básica, bem como do Ensino Superior, a fim de que reflexões e esclarecimentos sobre os mesmos pudessem ser oferecidos aos alunos. Os modelos escolares engessados em disciplinas tradicionais, por si só, no formato a que vêm sendo oferecidas ao longo das últimas décadas, não conseguem 
problematizar a realidade, a fim de que os estudantes adquiram consciência de tantas contradições que foram sendo estabelecidas ao longo da história.

No que diz respeito à figura dos professores, autores como Francisco e Libório (2009) constataram em suas pesquisas que, infelizmente, nem sempre os professores tomam iniciativas no enfrentamento das situações de bullying quando solicitados pelas crianças, muito mais por falta de conhecimento do que por omissão.

É fato que os professores no dia-a-dia das escolas muitas vezes são chamados a tomar decisões de forma imediata, fazendo com que os mesmos não tenham tempo hábil para entrar num processo de reflexão sobre sua ação (LIBÂNEO 2005). Contudo, alguns problemas persistem no cotidiano das escolas, tais como a violência escolar, exigindo dos mesmos uma postura mais consistente frente a sua persistência.

Munarin (2007) aponta que vários docentes valorizam muito, ou unicamente a tarefa de passar conteúdos, destituindo-os de qualquer compromisso com o social, ao criar a ilusão de que a escola é neutra. Essa falsa sensação de neutralidade, apenas reforça as relações que estão postas. E que por consequência geram um sentimento de conformismo social nos sujeitos.

\section{CONCLUSÃO}

Em nenhum momento houve a pretensão de se esgotar os estudos sobre essa temática. Sobretudo, porque as pesquisas sobre o bullying escolar continuam muito centradas em referenciais neoliberais. Nesse sentido, o referencial da Teoria Histórico-Cultural se abre como uma boa possibilidade para uma leitura mais crítica da realidade.

Com relação aos posicionamentos dos participantes da pesquisa, merece destaque aqueles que corroboram com a não sensibilização do sofrimento alheio, ou ainda que não se percebem como integrantes de uma coletividade social.

Há que se destacar ainda, a importância que esse referencial concede a educação escolar, pois por seu intermédio, os alunos poderão ter uma visão crítica sobre a sociedade como um todo; além de favorecer num posicionamento efetivo na busca pela transformação social. É importante frisar que a escola não é a redentora da humanidade, mas pode ser uma aliada dos interesses das camadas populares.

Por meio de uma prática revolucionária a escola poderia favorecer os alunos participantes dessa pesquisa, bem como qualquer outro estudante da escola pública a superarem posicionamentos superficiais e acríticos, ou seja, ao retomarem para si o controle consciente das 
transformações, das circunstâncias e de si mesmos, na superação da alienação, que desencadeia situações de bullying escolar e de não reconhecimento das "diferenças" expressas nos "outros", bem como no pleno desenvolvimento da personalidade humana.

\section{REFERÊNCIAS}

ABRAMOVAY, M. Violência no cotidiano das escolas. In: Mirian. Abramoay (Org.). Escola e violência. Brasília: UNESCO, UCB, 2003a, p. 67-87.

ALMEIDA, A. A vitimização entre pares em contexto escolar. In: C. Machado, R. A. Gonçalves (Orgs). Violência e vítimas de crimes: crianças. Coimbra: Quarteto, 2008, p.163-185.

ALMEIDA, A. A.; CAURCEL, M. J. Scan-bullying. Universidade do Minho: Braga, 2005.

FRANCISCO, M. V.; LIBÓRIO, R. M. C. Um estudo sobre bullying entre escolares do Ensino Fundamental. Psicologia: Reflexão e Crítica, Porto Alegre, v.22, n.2, p.200-207, mai./ago. 2009.

FRANCISCO, M. V.; LIBÓRIO, R. M. C. Reflexões sobre a superação de concepções individualizantes sobre o bullying escolar. In: A. I. M. RIBEIRO; I. A. T. VIOTTO FILHO; M. FURKOTTER; Y. U. F. LEITE (Orgs.). Educação contemporânea: caminhos, obstáculos e travessias. Cultura Acadêmica, 2011, p. 61-78.

LEONTIEV, A. N. O desenvolvimento do psiquismo. Lisboa: Livros Horizonte, 1978.

LIBÂNEO, J. C. Reflexidade e formação de professores: outra oscilação do pensamento pedagógico brasileiro? In: S. G. Pimenta; E. Ghedin (Orgs.). Professor reflexivo no Brasil: gênese e crítica de um conceito. São Paulo: Cortez, 2005, p. 53-79.

MUNARIN, J. C. A escola como espaço de convivência: a prevenção e a redução do bulismo escolar. 2007. 179f. Dissertação (Mestrado em Educação). Universidade do Oeste Paulista, Presidente Prudente.

PEREIRA, B.O. Para uma escola sem violência: estudo e prevenção das práticas agressivas entre crianças. Porto: Imprensa Portuguesa, 2002.

VYGOTSKY, L. S. Obras escogidas III: Problemas del desarrollo de la psique. 1.ed. Madrid: Visor, 1995. 383p.

VYGOTSKY, L. S. Obras escogidas II: Problemas de Psicología General. 2.ed. Madrid: A. Machado Libros, 2001. 484p. 